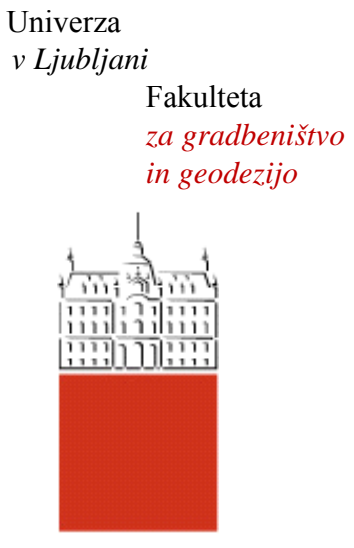

Jamova cesta 2

1000 Ljubljana, Slovenija

http://www3.fgg.uni-lj.si/

\section{DRUGG - Digitalni repozitorij UL FGG http://drugg.fgg.uni-lj.si/}

Ta članek je avtorjeva zadnja recenzirana različica, kot je bila sprejeta po opravljeni recenziji.

Prosimo, da se pri navajanju sklicujte na bibliografske podatke, kot je navedeno:
University
of Ljubljana

Faculty of

Civil and Geodetic

Engineering

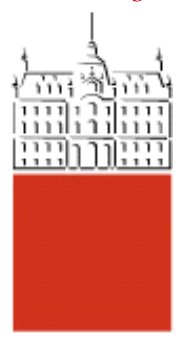

Jamova cesta 2

SI - 1000 Ljubljana, Slovenia

http://www3.fgg.uni-lj.si/en/

DRUGG - The Digital Repository http://drugg.fgg.uni-lj.si/

This version of the article is author's manuscript as accepted for publishing after the review process.

When citing, please refer to the publisher's bibliographic information as follows:

Hozjan, T., Planinc, I., Saje, M., Srpčič, S. 2011. Buckling of an axially restrained steel column under fire loading. International Journal of Structural Stability and Dynamics, 11,3: 451-472. DOI: $10.1142 / \mathrm{S} 0219455411004245$. 


\title{
BUCKLING OF AN AXIALLY RESTRAINED STEEL COLUMN UNDER FIRE LOADING
}

\author{
TOMAŽ HOZJAN ${ }^{1,2}$, IGOR PLANINC $^{2}$, MIRAN SAJE$^{2}$ AND STANISLAV SRPČIČ \\ ${ }^{1}$ Trimo d.d, Prijateljeva cesta 12, \\ 8210 Trebnje, Slovenia \\ ${ }^{2}$ University of Ljubljana, Faculty of Civil and Geodetic Engineering, Jamova 2, \\ SI-1115 Ljubljana, Slovenia \\ ssrpcic@fgg.uni-lj.si
}

Analytical procedure, based on the linearized stability analysis, is presented for the determination of the buckling load and the buckling temperature of a straight, geometrically perfect, axially loaded steel column subjected to an increasing temperature simulating fire conditions. The non-linear kinematical equations and the non-linearity of material are considered. The stress-strain relation for steel at the elevated temperature and the rules for reduction of material parameters due to increased temperature are taken from European standard EC 3. Theoretical findings are applied in the parametric analysis of a series of Euler's columns subjected to two parametric fires. It is found how the slenderness of the column, the material non-linearity, the temperature dependence of material parameters and the stiffness of restraints at supports effect the critical temperature. While these parameters have major influence on the critical temperature, they have no effect on the shape of the buckling mode.

Keywords: steel column; inelastic buckling; Reissner beam; high temperatures; critical temperature.

Received (Day Month Year)
Accepted (Day Month Year)

\section{Introduction}

Steel columns are very efficient structural elements both in terms of construction time and load bearing capacity. Steel is vulnerable to fire, however, and steel struc- 
2 Hozjan et al.

tures, potentially exposed to fire, require a particularly careful design. This especially holds true for steel columns as they are loaded in compression and are thus prone to buckling. With an increase of temperature, strength of steel and the stiffness of columns decrease leading to buckling at an even much lower level of external loading than at the room temperature. The practical design of columns exposed to fire is regulated by several building codes such as, e.g. Eurocode $3,{ }^{1}$ BS5950 2 and ISO $834 .{ }^{3}$ These standards offer simplified methods of analysis for isolated columns, which sometimes do not give sufficiently reliable quantitative predictions of the fire bearing capacity of a column, if it is a part of a frame.

A greater accuracy and a deeper insight into the thermal and mechanical behaviour of a column during fire can be obtained by the use of sophisticated mathematical models and modern numerical tools of solution. These formulations make it possible to consider and analyse various material models, fire load scenarios, boundary conditions, restraints and geometric imperfections. Such numerical models have also been applied to steel columns subjected to elevated temperatures, e.g. see Ref. 4-18. The research is often focused onto the effect of boundary restraints in a column caused by the presence of other members that frame into it, because their influence is of an utmost significance, and is often hard to predict computationally. ${ }^{8,9,11,15,19,20}$ Most of the formulations employ translational and rotational springs in modelling the restraints. Note that the restraints can either improve $^{21}$ or decrease the sustainability of the column to fire..$^{5,8,22}$

Analytical solutions are much more difficult to obtain and are only limited to the determination of fire resistance. The majority of analytical solutions revolves around the Merchant-Rankine equation and the second-order theory of beams. Skowronski ${ }^{23}$ derived an analytical formula for the fire resistance of a simple steel 
column. Toh et al. ${ }^{24}$ derived the formula of the critical temperature for axially and eccentrically loaded columns. Tang et al. ${ }^{25}$ improved their formulae by taking into account the effects of an initial crookedness, residual stresses, material models and the load eccentricity. Huang and $\operatorname{Tan}^{8}$ significantly improved the results presented in Tang et al. ${ }^{25}$ by additionally considering axial restraints. For columns with internal slide release Eisenberger and Ambarsumian ${ }^{26}$ determined the exact buckling load with use of exact stiffness matrix. With analytical tehnique, called the effective stiffness method Yang and Park ${ }^{27}$ developed the buckling analysis of constrained stepped columns.

The present article presents a systematic analytical procedure for the determination of the critical temperature of a straight, geometrically perfect, axially restraint and axially loaded steel column exposed to fire. A series of standard simplifications and assumptions need to be introduced, however, to enable the analytical solution to be derived. In particular, we assume that a steel column can be realistically modelled by a kinematically exact planar beam model of Reissner ${ }^{28}$ neglecting the effect of shear strain ${ }^{29}$. Next, we assume a non-linear, temperature dependent material law, which accounts for both viscous and plastic strains. The mathematical expressions for the stress-strain law of steel at high temperatures are taken from Eurocode $3^{1}$ along with the explicit expressions for temperature-dependent material parameters. As the walls of the steel sections are thin, we further assume that the temperature field in the column is uniform, but somewhat delayed with regard to temperature of the surrounding gas. ${ }^{1}$ After the thermo-mechanical equations are set up, the fundamental equilibrium solution of the column is obtained and the set of linearized equations at the fundamental equilibrium state is derived. The condition for the existence of the non-trivial solution of the linearized equations supplies 
4 Hozjan et al.

us with the value of the buckling temperature. This approach differs from that of, e.g. see Ref. $8,10,11,17$, who define the critical temperature of a compressed column as the temperature, for which the axial force, after an initial increase and a subsequent decrease, again reaches its value at the room temperature ${ }^{30}$. The details of the formulation are presented in Secs. 2 and 3. Sec. 4 presents the results of extensive parametric studies. The main findings are gathered in Conclusions.

\section{Basic theory}

\subsection{Preliminaries}

We consider a straight steel column of initial, undeformed length $L$ and a constant I-shaped cross-section. The column is centrically loaded with an axial force $F$ while simultaneously being exposed to fire (Fig. 1). The plane of deformation of the column is the plane $(x, z)$ of the Cartesian coordinate system $(x, y, z)$. The reference axis of the column is assumed to coincide with its centroidal axis.

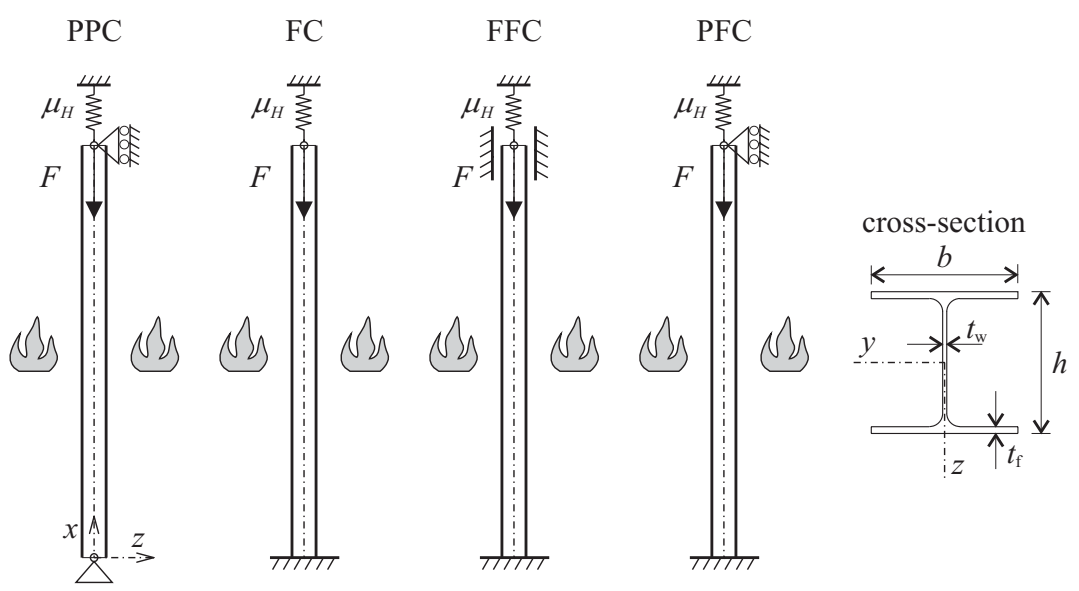

Fig. 1. Euler's columns and a typical cross-section. 
Modeling the interaction between fire and a structure is a hard job to do. The majority of models assume two independent analysis steps, the first one being the determination of the temperature field in the column and the second one consisting of the determination of the stress and strain field due to a combined effect of mechanical and temperature loads. In what follows, we only shortly describe the first step, while the second step is presented in detail.

\subsection{The temperature field}

The variation of temperature of gas in the fire compartment depends on many parameters, like the type and amount of fire load, area of the fire compartment, thermal properties of walls, area and the position of openings. ${ }^{31,32}$. To avoid such a complexity, one usually introduces the so called parametric temperature-time curves, which uniquely define explicit temperature-time relationships for typical situations. ${ }^{33}$ These relationships have been constructed from the results of extensive experimentations. After the time-variation of the gas temperature in the compartment has been obtained, we determine the temperature within the structure. This requires the integration of the differential equation of heat conduction. ${ }^{34} \mathrm{We}$ assume that temperature over the whole surface of the steel structure is uniform. Moreover, as typical steel sections are thin-walled, it is reasonable to assume a uniform temperature over the cross-sections. Then the temperature change becomes dependent only on time, yielding the solution as given in Eurocode $3^{1}$ :

$$
\Delta T_{\mathrm{s}, t}=k_{\mathrm{sh}} \frac{A_{\mathrm{m}} / V}{c_{\mathrm{a}} \rho_{\mathrm{a}}} \dot{h}_{\mathrm{net}, \mathrm{d}} \Delta t .
$$

Here $\Delta T_{\mathrm{s}, t}$ presents the temperature increment in time interval $\Delta t, k_{\mathrm{sh}}$ is the correction factor for the shadow effect, $m=A_{\mathrm{m}} / V$ is the section factor for unprotected 
6 Hozjan et al.

steel members, $A_{\mathrm{m}}$ is the surface area of the member per unit length $\left[\mathrm{m}^{2}\right], V$ is the volume of the member per unit length $\left[\mathrm{m}^{3}\right], c_{\mathrm{a}}$ is the specific heat of steel $[\mathrm{J} / \mathrm{kgK}]$, $\dot{h}_{\text {net,d }}$ is the design value of the net heat flux per unit area $\left[\mathrm{W} / \mathrm{m}^{2}\right]$, and $\rho_{\mathrm{a}}$ is the unit mass of steel $\left[\mathrm{kg} / \mathrm{m}^{3}\right]$. According to Eurocode $3^{1}$ the value of $\Delta t$ should be less or equal to 5 seconds.

Fig. 2 shows the development of temperature with time in an unprotected steel cross-section for two different parametric fire curves and for four different standard I-shaped cross-sections commercially labelled as HEA 300, HEB 400, HEA 500 and IPE 300 with thermal parameters according to Eurocode $3 .^{1}$ The characteristic parameters of the cross-sections are presented in Table 1. The two fire curves being considered are the ISO $834^{3}$ fire curve, and the natural fire curve ${ }^{13}$. The time increment equal to $\Delta t=2 \mathrm{~s}$ was used in evaluating Eq. (2.1). The graphs in Fig. 2 clearly show that smaller the section factor, larger is the delay of temperature. This becomes unimportant for temperatures higher than about $900^{\circ} \mathrm{C}$ (i.e., after about 50 minutes for the ISO 834 fire). In contrast, the delay is significant at any stage of the development of the natural fire.

(a) ISO 834

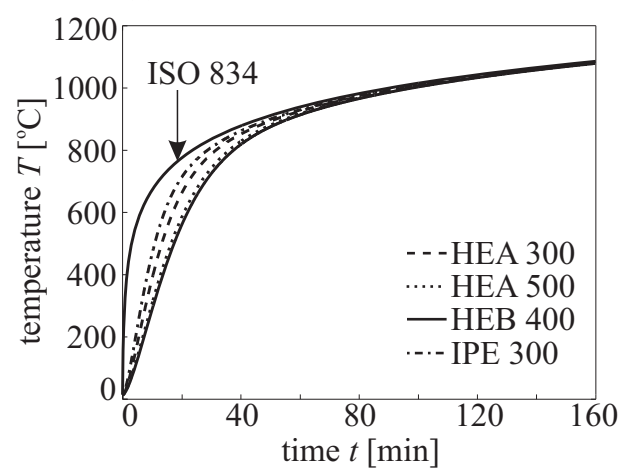

(b) natural fire

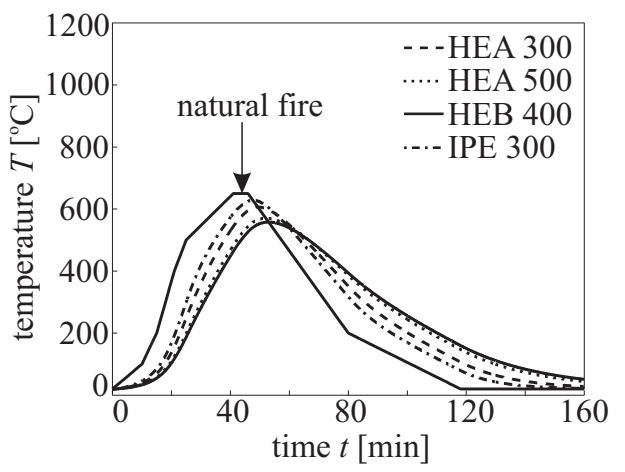

Fig. 2. Temperature vs. time curves for different steel sections. (a) ISO 834 (ISO 834, 1975) and (b) natural fire (Srpčič, 1991). 
Table 1. Geometrical data for cross-sections.

\begin{tabular}{lccccccc}
\hline & $m\left[\mathrm{~m}^{-1}\right]$ & $J\left[\mathrm{~cm}^{4}\right]$ & $A\left[\mathrm{~cm}^{2}\right]$ & $h[\mathrm{~cm}]$ & $b[\mathrm{~cm}]$ & $t_{\mathrm{f}}[\mathrm{cm}]$ & $t_{\mathrm{w}}[\mathrm{cm}]$ \\
\hline HEA 300 & 153 & 18260 & 113 & 29 & 30 & 1.40 & 0.85 \\
HEA 500 & 107 & 86970 & 198 & 79 & 30 & 2.30 & 1.20 \\
HEB 400 & 97 & 57680 & 198 & 40 & 30 & 2.40 & 1.35 \\
IPE 300 & 216 & 8360 & 53.8 & 30 & 15 & 1.07 & 0.71 \\
\hline
\end{tabular}

\subsection{The stress-strain field}

Once the temperature distributions in the structure during fire have been obtained, we may start the mechanical analysis. We find the solution in an incremental way. We divide the time of the duration of fire into time intervals $\left[t^{i-1}, t^{i}\right](i=1,2,3, \ldots)$. We assume that the stress and strain state at time $t^{i-1}$ is given and wish to obtain the state at time $t^{i}, i=1,2,3, \ldots$ The column is modelled by Reissner's geometrically exact beam theory, ${ }^{28}$ but with the effect of shear deformations being neglected. Taking into account that the distributed forces are absent and shear strains neglected, Reissner's theory yields the following governing equations:

$$
\begin{gathered}
f_{1}=1+u^{i \prime}-\left(1+\varepsilon^{i}\right) \cos \varphi^{i}=0, \\
f_{2}=w^{i \prime}+\left(1+\varepsilon^{i}\right) \sin \varphi^{i}=0, \\
f_{3}=\varphi^{i \prime}-\kappa^{i}=0, \\
f_{4}=\mathcal{H}^{i \prime}=0, \\
f_{5}=\mathcal{V}^{i \prime}=0,
\end{gathered}
$$


8 Hozjan et al.

$$
\begin{gathered}
f_{6}=\mathcal{M}^{i \prime}-\left(1+\varepsilon^{i}\right) \mathcal{Q}^{i}=0, \\
f_{7}=\mathcal{N}^{i}=\mathcal{H}^{i} \cos \varphi^{i}-\mathcal{V}^{i} \sin \varphi^{i}, \\
f_{8}=\mathcal{Q}^{i}=\mathcal{H}^{i} \sin \varphi^{i}+\mathcal{V}^{i} \cos \varphi^{i}, \\
f_{9}=\mathcal{N}^{i}=\int_{\mathcal{A}} \sigma^{i} \mathrm{~d} A, \\
f_{10}=\mathcal{M}^{i}=\int_{\mathcal{A}} z \sigma^{i} \mathrm{~d} A .
\end{gathered}
$$

Here $(\bullet)^{\prime}$ denotes the derivative with respect to $x$. In Eqs. $(2.2)-(2.11) \varepsilon^{i}$ and $\kappa^{i}$ are the extensional strain of the centroidal axis and its pseudocurvature, $u^{i}$ and $w^{i}$ are the components of the displacement vector of the centroidal axis of the column in $x$ and $z$ directions, and $\varphi^{i}$ is the cross-sectional rotation around $y . \mathcal{N}^{i}$ and $\mathcal{Q}^{i}$ are the axial and the shear force and $\mathcal{M}^{i}$ is the bending moment. $\mathcal{H}^{i}$ and $\mathcal{V}^{i}$ are the components of the resulting cross-sectional force with respect to the spatial axes $x$ and $z$, respectively. Eqs. (2.10) and (2.11) represent the constitutive equations of the cross-section, relating the axial force and the bending moment to the normal stress $\sigma^{i}$. Natural and boundary conditions corresponding to Eqs. (2.2)-(2.11) are (Fig. 1):

bottom, $x=0$ :

$$
\begin{gathered}
u^{i}(0)=0, \\
w^{i}(0)=0, \\
s_{1}^{1} \mathcal{M}^{i}(0)-s_{2}^{1} \varphi^{i}(0)=0 ;
\end{gathered}
$$


top, $x=L$ :

$$
\begin{gathered}
s_{H}\left(\mathcal{H}^{i}(L)+F\right)+\mu_{H} u^{i}(L)=0, \\
s_{1}^{2} \mathcal{V}^{i}(L)+s_{2}^{2} w^{i}(L)=0, \\
s_{3}^{2} \mathcal{M}^{i}(L)+s_{4}^{2} \varphi^{i}(L)=0 .
\end{gathered}
$$

Various combinations of boundary conditions of Euler's columns can be modeled by choosing appropriate parameters $s_{1}^{1}, s_{2}^{1}, s_{1}^{2}, s_{2}^{2}, s_{3}^{2}, s_{4}^{2}, s_{H}, \mu_{H} \in\{0,1\}$. Eqs. (2.2)(2.11) and (2.12)-(2.17) consist of 16 non-linear algebraic and differential equations for 16 unknown functions and parameters.

Based on the given stress and strain state at time $t^{i-1}$ and temperature at $t^{i}$, we can determine the strain $D^{i}$ at time $t^{i}$ of any point of the column by the equation

$$
D^{i}=D^{i-1}+\Delta D^{i}
$$

where $\Delta D^{i}(i=1,2,3, \ldots)$ is the increment of the total strain (also termed the geometrical deformation) in time interval $i$. The principle of additivity of strains is adopted that the total strain increment $\Delta D^{i}$ is the sum of the strain increments due to temperature, $\Delta D_{\mathrm{th}}^{i}$, stress, $\Delta D_{\sigma}^{i}$, and viscosity (creep) $\Delta D_{\mathrm{cr}}^{i}$ :

$$
\Delta D^{i}\left(T^{i}, \sigma^{i}, t^{i}, D_{\mathrm{cr}}^{i}\right)=\Delta D_{\mathrm{th}}^{i}\left(T^{i}\right)+\Delta D_{\sigma}^{i}\left(T^{i}\right)+\Delta D_{\mathrm{cr}}^{i}\left(\sigma^{i}, T^{i}, D_{\mathrm{cr}}^{i}, t^{i}\right) .
$$

In Eq. (2.19), the quantities in the parentheses indicate the dependence of the increment on the particular quantity. The functional relation of the temperature strain increment, $\Delta D_{\mathrm{th}}^{i}\left(T^{i}\right)$, is provided by Eurocode $3^{1}$. There the total rather than the incremental temperature strain, $D_{\mathrm{th}}$, is given with a formal expression 
$D_{\mathrm{th}}=f(T) ;^{1}$ thus, $\Delta D_{\mathrm{th}}^{i}\left(T^{i}\right)=f\left(T^{i}\right)-f\left(T^{i-1}\right)$. The stress-dependent strain increment, $\Delta D_{\sigma}^{i}$, also termed the mechanical strain increment, is assumed to be equal to the sum of elastic and plastic strains, $\Delta D_{\sigma}^{i}\left(T^{i}\right)=\Delta D_{\mathrm{e}}^{i}\left(T^{i}\right)+\Delta D_{\mathrm{p}}^{i}\left(T^{i}\right)$. The viscous strain increment, $\Delta D_{\mathrm{cr}}^{i}$, is, in general, a function of the current temperature, stress, time and the total viscous strain $D_{\mathrm{cr}}^{i} \cdot{ }^{13}$ In experiments, however, it is very difficult to determine separately, in unique and accurate way, plastic and viscous parts of the strain at high temperature. This is one of the reasons why it is often assumed that both the plastic and viscous strains can be treated as a combined plastic strain. ${ }^{1,35}$ In such a case, $\Delta D^{i}$ is given by

$$
\Delta D^{i}\left(T^{i}\right)=\Delta D_{\mathrm{th}}^{i}\left(T^{i}\right)+\Delta D_{\sigma}^{i}\left(T^{i}\right)
$$

where $\Delta D_{\sigma}^{i}$ now combines the contributions of both plastic and viscous strains. Such a simplified material model for steel at high temperature is also adopted by Eurocode $3^{1}$ and is given as

$$
\sigma^{i}\left(D_{\sigma}^{i}\right)= \begin{cases}E_{\mathrm{s}, T} D_{\sigma}^{i} & \left|D_{\sigma}^{i}\right| \leq D_{\mathrm{p}, T} \\ f_{\mathrm{p}, T}-c+(b / a) \sqrt{\left[a^{2}-\left(D_{\mathrm{y}, T}-D_{\sigma}^{i}\right)^{2}\right]} & D_{\mathrm{p}, T}<\left|D_{\sigma}^{i}\right| \leq D_{\mathrm{y}, T} \\ f_{\mathrm{y}, T}\left[1-\left(D_{\sigma}^{i}-D_{\mathrm{t}}\right) /\left(D_{\mathrm{u}}-D_{\mathrm{t}}\right)\right] & D_{\mathrm{y}, T}<\left|D_{\sigma}^{i}\right| \leq D_{\mathrm{t}} \\ f_{\mathrm{y}, T}[1 & D_{\mathrm{t}}<\left|D_{\sigma}^{i}\right| \leq D_{\mathrm{u}}\end{cases}
$$

This model will also be used in our formulation. In Eq. (2.21) $D_{\mathrm{p}, T}$ denotes the strain at the proportional limit, $D_{\mathrm{y}, T}$ is the yield strain, and $E_{\mathrm{s}, T}$ is elastic modulus. Parameters $D_{\mathrm{p}, T}, D_{\mathrm{y}, T}, f_{\mathrm{p}, T}, f_{\mathrm{y}, T}$ and $E_{\mathrm{s}, T}$ are dependent on $a, b$ and $c$, which are fully described in Eurocode $3^{1}$. The remaining material parameters in Eq. (2.21) are $D_{\mathrm{t}}=0.15$ and $D_{\mathrm{u}}=0.20$ and are temperature independent. The symbolic graph of the stress-strain curve for steel at high temperature is depicted in Fig. 3a. The temperature-dependence of material parameters is considered via the reduction 
factors $k_{\mathrm{p}, T}, k_{\mathrm{y}, T}$ and $k_{E, T}$; i.e., the change of the proportional limit is given by $f_{\mathrm{p}, T}=k_{\mathrm{p}, T} f_{\mathrm{y}, 20}$; yield strength is given by $f_{\mathrm{y}, T}=k_{\mathrm{y}, T} f_{\mathrm{y}, 20}$; and elastic modulus by $f_{E, T}=k_{E, T} E_{\mathrm{s}, 20}$. Here $f_{\mathrm{y}, 20}$ and $E_{\mathrm{s}, 20}$ denote the values of $f_{\mathrm{y}}$ and $E_{\mathrm{s}}$ at room temperature $\left(20^{\circ} \mathrm{C}\right)$. The variation of the reduction parameters with temperature is displayed in Fig. 3b. ${ }^{1}$

(a) constitutive model

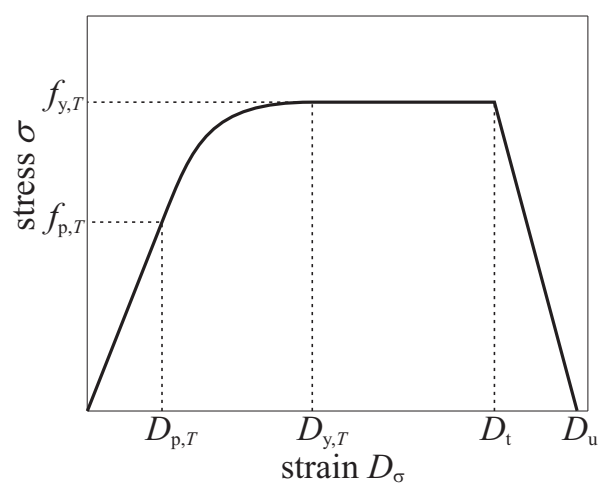

(b) reduction factors

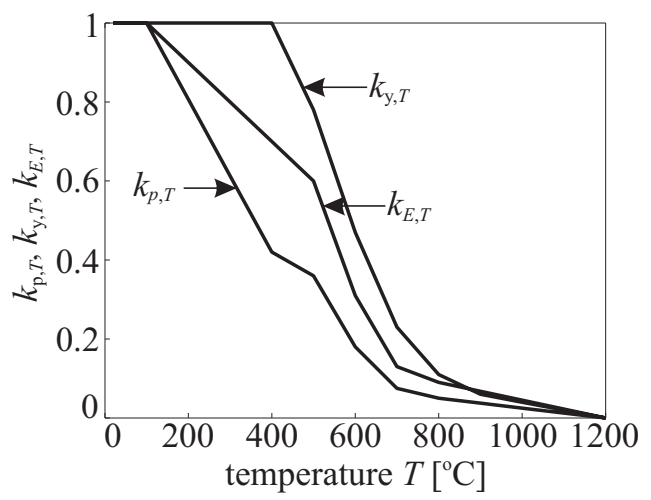

Fig. 3. (a) Stress-strain relationship for steel in tension and compression according to Eurocode $3^{1} ;$ (b) temperature-dependent reduction factors.

The development of the stress-strain state in a steel column during fire is fully determined by the system of 10 non-linear algebraic and differential Eqs. (2.2)(2.11) for 10 unknown functions of $x: u^{i}, w^{i}, \varphi^{i}, \mathcal{N}^{i}, \mathcal{Q}^{i}, \mathcal{M}^{i}, \varepsilon^{i}, \kappa^{i}, \mathcal{H}^{i}, \mathcal{V}^{i}$. The general analytical solution is not available and the solution must therefore be obtained numerically, e.g. by the finite element method. In contrast, the buckling loads can be obtained analytically. The derivation is given in the next section. 
12 Hozjan et al.

\section{Linearized buckling analysis}

\subsection{Fundamental equilibrium path}

We seek the loss of stability of a column subjected to both an axial compression load and an increasing temperature. Prior to buckling, such a column remains straight and vertical. Hence the fundamental equilibrium solution is characterized by the condition $\varphi^{i}=0$. Inserting $\varphi^{i}=0$ in Eqs. (2.2)-(2.9) gives:

$$
\begin{gathered}
u^{i \prime}+\varepsilon^{i}=0, \\
w^{i \prime}=0, \\
\kappa^{i}=0, \\
\mathcal{H}^{i \prime}=0, \\
\mathcal{V}^{i \prime}=0, \\
\mathcal{M}^{i \prime}-\left(1+\varepsilon^{i}\right) \mathcal{Q}^{i}=0, \\
\mathcal{N}^{i}=\mathcal{V}^{i} .
\end{gathered}
$$

As $\kappa^{i}=0$ and $D_{\text {th }}^{i}$ is constant with respect to $x, y, z$, Eqs. (2.10) and (2.11), when combined with Eq. (2.20), can be written in the form

$$
\mathcal{N}^{i}=\sigma^{i}\left(\varepsilon^{i}, \kappa^{i}=0, D_{\mathrm{th}}^{i}, T^{i}\right) A,
$$




$$
\mathcal{M}^{i}=0
$$

The integration of Eqs. (3.4) and (3.5) gives $\mathcal{H}^{i}(x)=\mathcal{H}^{i}(0)=$ const. and $\mathcal{V}^{i}(x)=$ $\mathcal{V}^{i}(0)=$ const. Considering the result in Eqs. (3.7)-(3.9) gives $\mathcal{N}^{i}(x)=$ const., $\mathcal{Q}^{i}(x)=$ const. and $\varepsilon^{i}=$ const. From Eqs. (3.6), (3.8) and (3.10) it follows that $\mathcal{Q}^{i}(x)=\mathcal{V}^{i}(x)=0$. Thus, the fundamental equilibrium of the column is described with the following system of non-linear equations:

$$
\begin{gathered}
u^{i}=\varepsilon^{i} x, \\
w^{i}=0, \\
\varphi^{i}=0, \\
\mathcal{H}^{i}=\mathcal{H}^{i}(0)=\text { const. } \\
\mathcal{V}^{i}=0, \\
\mathcal{M}^{i}=0, \\
\kappa^{i}\left(\varepsilon^{i}, \kappa^{i}=0, D_{\text {th }}^{i}, T^{i}\right) A, \\
\mathcal{Q}^{i}=\mathcal{V}^{i}=0, \\
\mathcal{N}^{i}=\mathcal{H}^{i}=\text { const. }
\end{gathered}
$$


and the boundary condition (3.39)

$$
\left(s_{H} \mathcal{H}^{i}(L)+F\right)+\mu_{H} u^{i}(L)=0 .
$$

The remaining boundary conditions, Eqs. (2.12)-(2.14), (2.16)-(2.17), are satisfied identically. Table 2 displays two different fundamental solutions corresponding to Eq. (3.21) with $s_{H}=0, F=0$, and $s_{H}=1$, respectively. The solution of the above given non-linear algebraic equations must be obtained iteratively.

Table 2. Geometrical data for cross-sections.

\begin{tabular}{|c|c|c|c|c|}
\hline & boundary condition & $\varepsilon^{i}(x)$ & $u^{i}(x)$ & $\mathcal{N}^{i}(x)=\mathcal{H}^{i}(x)$ \\
\hline (1) & $u^{i}(L)=0$ & 0 & 0 & $\sigma^{i}\left(\varepsilon^{i}=0, \kappa^{i}=0, D_{\mathrm{th}}^{i}, T^{i}\right) A=$ const. \\
\hline$(2)$ & $\mathcal{H}^{i}(L)=-F-\mu_{H}^{*} u^{i}(L)$ & const. $\neq 0$ & $\varepsilon^{i} x$ & $-F-\mu_{H}^{*} \varepsilon^{i} L$ \\
\hline
\end{tabular}

Note: ${ }^{*} \mu_{H} \neq \infty$

\subsection{Buckling load}

The linear theory of stability enables to find the critical point on the fundamental equilibrium path by the linearization of the governing equations. ${ }^{36}$ It is convenient to write Eqs. $(2.2)-(2.11)$ in a vector form: $\mathbf{f}=\left[f_{1}, f_{2}, \ldots, f_{10}\right]^{T}=\mathbf{0}$. The arguments of functions $f_{i}$ are also written in the vector form: $\mathbf{x}=\left[u^{i \prime}, \varepsilon^{i}, \varphi^{i}, w^{i \prime}, \varphi^{i \prime}, \kappa^{i}, \mathcal{H}^{i \prime}\right.$, $\left.\mathcal{V}^{i \prime}, \mathcal{M}^{i \prime}, \mathcal{Q}^{i}, \mathcal{N}^{i}\right]$. The linearization of the functional $\mathbf{f}$ is the directional derivative of $\mathbf{f}(\mathbf{x})$ in the direction of $\delta \mathbf{x}$

$$
\delta \mathbf{f}=\left.\frac{\mathrm{d}}{\mathrm{d} \alpha}\right|_{\alpha=0} \mathbf{f}(\mathbf{x}+\alpha \delta \mathbf{x}) .
$$

In the context of the stability theory, $\delta \mathbf{x}$ means the perturbation in $\mathbf{x}$.

The linearization of equilibrium Eqs. (2.2)-(2.11) when written at the fundamental equilibrium solution gives 


$$
\begin{gathered}
\delta f_{1}=\delta u^{i \prime}-\delta \varepsilon^{i}=0, \\
\delta f_{2}=\delta w^{i \prime}+\left(1+\varepsilon^{i}\right) \delta \varphi^{i}=0, \\
\delta f_{3}=\delta \varphi^{i \prime}-\delta \kappa^{i}=0,
\end{gathered}
$$

$$
\delta f_{4}=\delta \mathcal{H}^{i \prime}=0
$$$$
\delta f_{5}=\delta \mathcal{V}^{i \prime}=0
$$

$$
\delta f_{6}=\delta \mathcal{M}^{i \prime}-\left(1+\varepsilon^{i}\right) \delta \mathcal{Q}^{i}=0
$$

$$
\delta f_{7}=\delta \mathcal{N}^{i}=\delta \mathcal{H}^{i}
$$

$$
\delta f_{8}=\delta \mathcal{Q}^{i}=\delta \mathcal{V}^{i}+\mathcal{N}^{i} \delta \varphi^{i}
$$

$$
\begin{gathered}
\delta f_{9}=\delta \mathcal{N}^{i}=C_{11}^{i}\left(\varepsilon^{i}, \kappa^{i}=0, D_{\mathrm{th}}^{i}, T^{i}\right) \delta \varepsilon^{i}+C_{12}^{i}\left(\varepsilon^{i}, \kappa^{i}=0, D_{\mathrm{th}}^{i}, T^{i}\right) \delta \kappa^{i}, \\
\delta f_{10}=\delta \mathcal{M}^{i}=C_{21}^{i}\left(\varepsilon^{i}, \kappa^{i}=0, D_{\mathrm{th}}^{i}, T^{i}\right) \delta \varepsilon^{i}+C_{22}^{i}\left(\varepsilon^{i}, \kappa^{i}=0, D_{\mathrm{th}}^{i}, T^{i}\right) \delta \kappa^{i} .
\end{gathered}
$$

In Eqs. (3.31) and (3.32), $C_{11}^{i}, C_{12}^{i}=C_{21}^{i}, C_{22}^{i}$ are the components of the tangent constitutive matrix of the cross-section. Due to the symmetry of the cross-section with respect to the plane $(x, z)$ and a uniform temperature field in the column, these components assume rather simple forms:

$$
C_{11}^{i}\left(\varepsilon^{i}, \kappa^{i}=0, D_{\mathrm{th}}^{i}, T^{i}\right)=\frac{\partial \sigma^{i}}{\partial \varepsilon^{i}} A=E_{\mathrm{t}}^{i} A=\text { const. }
$$


16 Hozjan et al.

$$
\begin{gathered}
C_{12}^{i}\left(\varepsilon^{i}, \kappa^{i}=0, D_{\mathrm{th}}^{i}, T^{i}\right)=C_{21}\left(\varepsilon^{i}, \kappa^{i}=0, D_{\mathrm{th}}^{i}, T^{i}\right)=0, \\
C_{22}^{i}\left(\varepsilon^{i}, \kappa^{i}=0, D_{\mathrm{th}}^{i}, T^{i}\right)=\frac{\partial \sigma^{i}}{\partial \varepsilon^{i}} J=E_{\mathrm{t}}^{i} J=\text { const.. }
\end{gathered}
$$

The linearized equilibrium Eqs. (3.23)-(3.32) must be complemented with the linearized boundary conditions (2.12)-(2.17). After the linearization has been performed we have:

bottom, $x=0$ :

$$
\begin{gathered}
\delta u^{i}(0)=0, \\
\delta w^{i}(0)=0, \\
s_{1}^{1} \delta \mathcal{M}^{i}(0)-s_{2}^{1} \delta \varphi^{i}(0)=0,
\end{gathered}
$$

top, $x=L$ :

$$
\begin{gathered}
s_{H} \delta \mathcal{H}^{i}(L)+\mu_{H} \delta u^{i}(L)=0 \\
s_{1}^{2} \delta \mathcal{V}^{i}(L)+s_{2}^{2} \delta w^{i}(L)=0 \\
s_{3}^{2} \delta \mathcal{M}^{i}(L)+s_{4}^{2} \delta \varphi^{i}(L)=0 .
\end{gathered}
$$

Eqs. (3.23)-(3.32) constitute the system of 10 algebraic-differential equations which have to be solved with respect to their boundary conditions (3.36)-(3.41) for the perturbations $\delta \mathbf{x}$ from the equilibrium state. After a systematic elimination of the unknowns is made, we end up with the system of two differential equations for $\delta u^{i}$ and $\delta w^{i}$ :

$$
\begin{gathered}
\delta u^{i \prime \prime}=0, \\
\delta w^{i \prime \prime \prime \prime}+k^{i^{2}} \delta w^{i \prime \prime}=0,
\end{gathered}
$$

in which the buckling load parameter $k^{i}$ has been introduced as 


$$
k^{i^{2}}=\frac{\left(1+\varepsilon^{i}\right)\left|\mathcal{N}^{i}\right|}{E_{\mathrm{t}}^{i} J}>0 .
$$

The general solutions of Eqs. (3.42) and (3.43) are

$$
\begin{gathered}
\delta u^{i}(x)=\mathcal{K}_{1}^{i} x+\mathcal{K}_{2}^{i}, \\
\delta w^{i}(x)=\mathcal{C}_{1}^{i} \cos k^{i} x+\mathcal{C}_{2}^{i} \sin k^{i} x+\mathcal{C}_{3}^{i} x+\mathcal{C}_{4}^{i} .
\end{gathered}
$$

The unknown integration constants, $\mathcal{K}_{1}^{i}, \mathcal{K}_{2}^{i}, \mathcal{C}_{1}^{i}, \mathcal{C}_{2}^{i}, \mathcal{C}_{3}^{i}$ and $\mathcal{C}_{4}^{i}$, in Eqs. (3.45) and (3.46) are obtained from the requirement that the solutions (3.45) and (3.46) satisfy the linearized static and kinematic boundary conditions (3.36)-(3.41). By their imposition to the solutions (3.45) and (3.46), we get a system of six homogeneous algebraic linear equations for six unknown integration constants $\mathcal{K}_{1}^{i}, \mathcal{K}_{2}^{i}, \mathcal{C}_{1}^{i}, \mathcal{C}_{2}^{i}, \mathcal{C}_{3}^{i}$, $\mathcal{C}_{4}^{i}$, which can be written in a matrix form as

$$
\boldsymbol{L}_{\mathrm{T}}^{i} \boldsymbol{y}^{i}=\mathbf{0},
$$

where $\boldsymbol{L}_{\mathrm{T}}^{i}$ and $\boldsymbol{y}^{i}$ denote the tangent matrix of the current equilibrium state on the fundamental path, and the vector of unknown constants, respectively. The nontrivial solution of Eq. (3.47) is only possible if

$$
\operatorname{det} \boldsymbol{L}_{\mathrm{T}}^{i}=0
$$

Because Eqs. (3.45)-(3.46) are separated, matrix $\boldsymbol{L}_{\mathrm{T}}^{i}$ can be written as a product of two matrices, i.e. $\boldsymbol{L}_{\mathrm{T}}^{i}=\boldsymbol{H}_{\mathrm{T}}^{i} \boldsymbol{K}_{\mathrm{T}}^{i}$. Thus, condition (3.48) appears to be equivalent to

$$
\operatorname{det} \boldsymbol{L}_{\mathrm{T}}^{i}=\operatorname{det} \boldsymbol{H}_{\mathrm{T}}^{i} \operatorname{det} \boldsymbol{K}_{\mathrm{T}}^{i}=0 .
$$


Here matrix $\boldsymbol{H}_{\mathrm{T}}^{i}$ depends solely on $\mathcal{K}_{1}^{i}, \mathcal{K}_{2}^{i}$, and matrix $\boldsymbol{K}_{\mathrm{T}}^{i}$ is expressed solely with $\mathcal{C}_{1}^{i}, \mathcal{C}_{2}^{i}, \mathcal{C}_{3}^{i}, \mathcal{C}_{4}^{i}$. It is easy to show that $\operatorname{det} \boldsymbol{H}_{\mathrm{T}}^{i} \neq 0$ for any $\mathcal{K}_{1}^{i}$ and $\mathcal{K}_{2}^{i}$; thus condition (3.49) implies

$$
\operatorname{det} \boldsymbol{K}_{\mathrm{T}}^{i}=0
$$

The condition, enforced by Eq. (3.50), determines the critical point of the structure.

This is either limit or bifurcation point. The bifurcation point results in buckling of the column and most probably its loss of stability; for slender columns, this is a dominant form of instability if the column is exposed to the fire.

The explicit form of matrix $\boldsymbol{K}_{\mathrm{T}}^{i}$ can easily be deduced and is given by

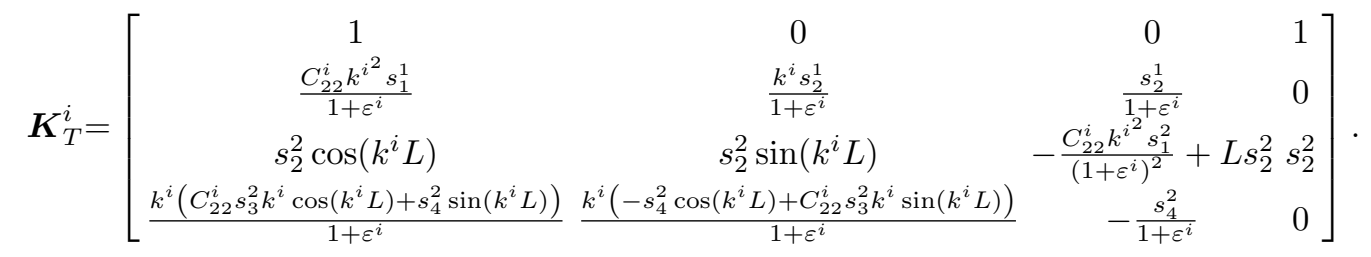

Its determinant reads

$$
\operatorname{det} \boldsymbol{K}_{\mathrm{T}}^{i}=\mathcal{A}^{i}+\mathcal{B}^{i} \cos \left(k^{i} L\right)+k_{\mathrm{cr}} \mathcal{C}^{i} \sin \left(k^{i} L\right),
$$

where

$$
\mathcal{A}^{i}=2\left(1+\varepsilon^{i}\right)^{2} s_{2}^{1} s_{2}^{2} s_{4}^{2},
$$

$\mathcal{B}^{i}=-2\left(1+\varepsilon^{i}\right)^{2} s_{2}^{1} s_{2}^{2} s_{4}^{2}+k^{i^{4}} C_{22}^{i^{2}} s_{1}^{2}\left(s_{3}^{2} s_{2}^{1}+s_{1}^{1} s_{4}^{2}\right)-k^{i^{2}} L\left(1+\varepsilon^{i}\right)^{2} C_{22}^{i} \mu_{\mathrm{V}}\left(s_{3}^{2} s_{2}^{1}+s_{1}^{1} s_{4}^{2}\right)$,

$$
\begin{gathered}
\mathcal{C}^{i}=C_{22}^{i} s_{3}^{2}\left(C_{22}^{i} k^{i^{2}} s_{1}^{1}\left(-C_{22}^{i} k^{i^{2}} s_{1}^{2}+L\left(1+\varepsilon^{i}\right)^{2} s_{2}^{2}\right)\right)+C_{22}^{i}\left(1+\varepsilon^{i}\right)^{2} s_{2}^{1} s_{2}^{2} s_{3}^{2}+ \\
\left(C_{22}^{i} s_{1}^{1}\left(1+\varepsilon^{i}\right)^{2} s_{2}^{2}+C_{22}^{i} k^{i^{2}} s_{1}^{2} s_{2}^{1}-L\left(1+\varepsilon^{i}\right)^{2} s_{2}^{2} s_{2}^{1}\right) s_{4}^{2}
\end{gathered}
$$

and $k_{\mathrm{cr}}^{i^{2}}=\frac{\left(1+\varepsilon_{\mathrm{cr}}^{i}\right)\left|\mathcal{N}_{\mathrm{cr}}^{i}\right|}{E_{\mathrm{t}}^{i} J}$. Condition (3.50) along with Eqs. (40) and (42) evaluated at the fundamental solution (see Table 2),

$$
\operatorname{det} \boldsymbol{K}_{\mathrm{T}}^{i}=0
$$




$$
\mathcal{N}_{\mathrm{cr}}+F_{\mathrm{cr}}+\mu_{H} \varepsilon_{\mathrm{cr}} L=0
$$

$$
\mathcal{N}_{\text {cr }}-\sigma_{\text {cr }} A=0
$$

constitute a system of three algebraic equations for three unknowns in the critical point: critical axial force $\mathcal{N}_{\text {cr }}$, critical axial strain $\varepsilon_{\text {cr }}$ and critical temperature $T_{\text {cr }}$ of steel column at the instant of buckling. For an axially restrained and unloaded column $\left(\mu_{H}=\infty\right)$, buckling occurs only due to the increase of temperature; thus $\varepsilon_{\mathrm{cr}}=0$ and $F_{\mathrm{cr}}=0$, and the buckling load follows from Eqs. (3.52) and (3.54). This time the only unknowns are $\mathcal{N}_{\text {cr }}$ and $T_{\text {cr }}$.

In the present article, we discuss only the four classical boundary conditions of Euler (Fig. 1). As then the boundary conditions are relatively simple, Eq. (3.52) can even further be simplified. For a simply supported column, labelled PPC (pin-pin), this equation takes the form:

$$
\operatorname{det} \boldsymbol{K}_{\mathrm{T}}=C_{22, \mathrm{cr}}^{2} k_{\mathrm{cr}}^{3}\left(1+\varepsilon_{\mathrm{cr}}\right) L \sin \left(k_{\mathrm{cr}} L\right)=0
$$

Its solution is $k_{\mathrm{cr}} L=n \pi(n=1,2, \ldots)$. For a given load $F=F_{\mathrm{cr}}$, the smallest value of the critical temperature, $T_{\mathrm{cr}}$, appears to be at $n=1$. Once $k_{\mathrm{cr}} L=\pi$ has been established, the critical force $\mathcal{N}_{\text {cr }}$ is found from Eq. (3.54). For a partially restrained pin-pin column $\left(\mu_{H} \neq \infty\right)$, the critical temperature is determined from Eq. (3.44), i.e. from $\left(1+\varepsilon_{\mathrm{cr}}\right)\left|\mathcal{N}_{\mathrm{cr}}\right|=\frac{E_{\mathrm{t}} J \pi^{2}}{L^{2}}$. Similarly, for an axially restrained column $\left(\mu_{H}=\infty\right)$, we have $\mathcal{N}_{\mathrm{cr}}=A\left|\sigma_{\mathrm{cr}}\right|=\frac{E_{\mathrm{t}} J \pi^{2}}{L^{2}}$. The determination of the critical values of the remaining Euler's columns is analogous and need not to be explained further. The solutions are displayed in Table 3. 
Table 3. Euler's columns. Critical force, $\mathcal{N}_{\text {cr }}$.

\begin{tabular}{cll}
\hline Type of the column & \multicolumn{1}{c}{$\operatorname{det} \boldsymbol{K}_{\mathrm{T}}=0\left(\mu_{H} \neq \infty\right)$} & \multicolumn{1}{c}{$\operatorname{det} \boldsymbol{K}_{\mathrm{T}}=0\left(\mu_{H}=\infty\right)$} \\
\hline PPC & $\left(1+\varepsilon_{\mathrm{cr}}\right)\left|\mathcal{N}_{\mathrm{cr}}\right|^{*}=\frac{E_{t} J \pi^{2}}{(L)^{2}}$ & $\mathcal{N}_{\mathrm{cr}}=A\left|\sigma_{\mathrm{cr}}\right|=\frac{E_{t} J \pi^{2}}{(L)^{2}}$ \\
FC & $\left(1+\varepsilon_{\mathrm{cr}}\right)\left|\mathcal{N}_{\mathrm{cr}}\right|^{*}=\frac{E_{\mathrm{t}} J \pi^{2}}{(2 L)^{2}}$ & $\mathcal{N}_{\mathrm{cr}}=A\left|\sigma_{\mathrm{cr}}\right|=\frac{E_{\mathrm{t}} J \pi^{2}}{(2 L)^{2}}$ \\
FFC & $\left(1+\varepsilon_{\mathrm{cr}}\right)\left|\mathcal{N}_{\mathrm{cr}}\right|^{*}=\frac{E_{\mathrm{t}} J \pi^{2}}{(0.5 L)^{2}}$ & $\mathcal{N}_{\mathrm{cr}}=A\left|\sigma_{\mathrm{cr}}\right|=\frac{E_{\mathrm{t}} J \pi^{2}}{(0.5 L)^{2}}$ \\
PFC & $\left(1+\varepsilon_{\mathrm{cr}}\right)\left|\mathcal{N}_{\mathrm{cr}}\right|^{*}=\frac{E_{\mathrm{t}} J \pi^{2}}{(0.69915565 \ldots L)^{2}}$ & $\mathcal{N}_{\mathrm{cr}}=A\left|\sigma_{\mathrm{cr}}\right|=\frac{E_{\mathrm{t}} J \pi^{2}}{(0.69915565 \ldots L)^{2}}$ \\
\hline
\end{tabular}

Note: ${ }^{*} \mathcal{N}_{\mathrm{cr}}=-F_{\mathrm{cr}}-\mu_{H} \varepsilon_{\mathrm{cr}} L$

\subsection{Description of the solution method}

As the viscous strains of the material model considered here are accounted for only indirectly (as a part of plastic strains), the systems of non-linear Eqs. (3.52)-(3.54) and (2.1) are uncoupled and can be solved separately. In the first step, we solve algebraic Eqs. (3.52)-(3.54) for the three critical values $T_{\text {cr }}, \mathcal{N}_{\text {cr }}$ and $\varepsilon_{\text {cr }}$. In the second solution step, we solve Eq. (2.1) for $t_{\mathrm{cr}}$. Similarly, if we choose $\mathcal{N}_{\mathrm{cr}}, \varepsilon_{\mathrm{cr}}, L_{\mathrm{cr}}$ as the basic unknowns, these are determined in the first solution step, while $t_{\mathrm{cr}}$ is determined later on from Eq. (2.1).

The accuracy of the solutions of Eqs. (3.52)-(3.54) is solely dependent on the machine precision of a computer and the round-off errors. In contrast, the accuracy of $t_{\mathrm{cr}}$ also depends on the time step, $\Delta t$.

\section{Parametric studies}

The parametric studies presented in this section will show the effects of fire regime, boundary conditions, material and geometrical properties and the external load on the buckling resistance of steel columns in fire. The material model of steel for the high-temperature range employed here follows the building standard Eurocode $3^{1}$, and steels labeled as S 235, S 275 and S 355 are used. The values of yield strengths 
and elastic moduli at room temperature are shown in Table 4 . In all the parametric studies, standard sections with commercial labels HEA 300, HEA 500, HEB 400 and IPE 300 are used.

Table 4. Material properties of steel at room temperature $\left(T=20^{\circ} \mathrm{C}\right)$.

\begin{tabular}{lcc}
\hline & $f_{\mathrm{y}, 20}\left[\mathrm{kN} / \mathrm{cm}^{2}\right]$ & $E_{\mathrm{s}, 20}\left[\mathrm{kN} / \mathrm{cm}^{2}\right]$ \\
\hline $\mathrm{S} 235$ & 23.5 & 21000 \\
$\mathrm{~S} 275$ & 27.5 & 21000 \\
$\mathrm{~S} 355$ & 35.5 & 21000 \\
\hline
\end{tabular}

The stress-strain curves of steel at various temperatures are depicted in Fig. 4. As observed from Fig. 4, temperature is a significant factor of strength and ductility of steel (Fig. 4a). Of a particular importance to the bearing capacity of columns is that the ductility is much larger at high temperatures. Fig. 4b shows changing of the elastic modulus with strain at various temperatures. Note that strength and elastic modulus of steel at $800^{\circ} \mathrm{C}$ take only about $10 \%$ of their values at the room temperature. The decrease of the ultimate axial bearing capacity of the cross-section with temperature is presented in a numerical form in Table 5.

Table 5. The variation of the ultimate axial bearing capacity of the crosssection, $\left\|\mathcal{N}_{\mathrm{ult}}\right\|=\mathcal{N}_{\mathrm{ult}, T} / \mathcal{N}_{\mathrm{ult}, 20}=f_{\mathrm{y}, T} / f_{\mathrm{y}, 20}$, and the related ultimate axial strain, $D_{\sigma, \text { ult }}$, with temperature.

\begin{tabular}{ccccccccc}
\hline$T\left[{ }^{\circ} \mathrm{C}\right]$ & 20 & 200 & 300 & 400 & 500 & 600 & 700 & 800 \\
\hline$\left\|\mathcal{N}_{\mathrm{ult}}\right\|$ & 1 & 1 & 1 & 1 & 0.78 & 0.47 & 0.23 & 0.11 \\
$\left|D_{\sigma, \mathrm{ult}}\right|[\% / \circ]$ & 1.1095 & 20 & 20 & 20 & 20 & 20 & 20 & 20 \\
\hline
\end{tabular}

As already discussed, the accuracy of $T_{\mathrm{cr}}$ is only dependent on the machine precision, while the accuracy of $t_{\mathrm{cr}}$ also depends on the time step $\Delta t$. This is illustrated 
(a)

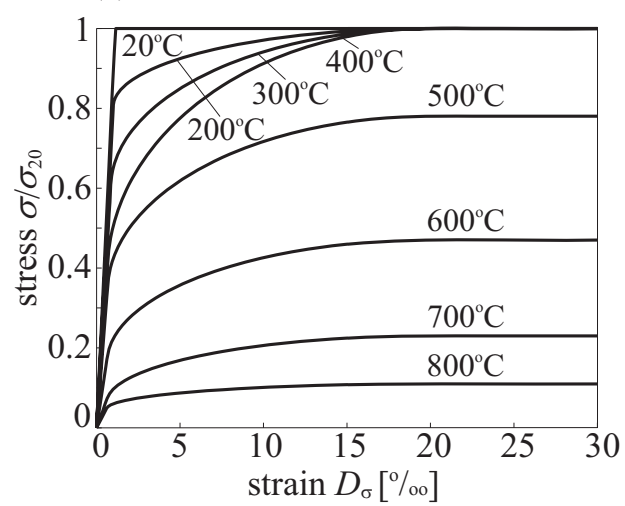

(b)

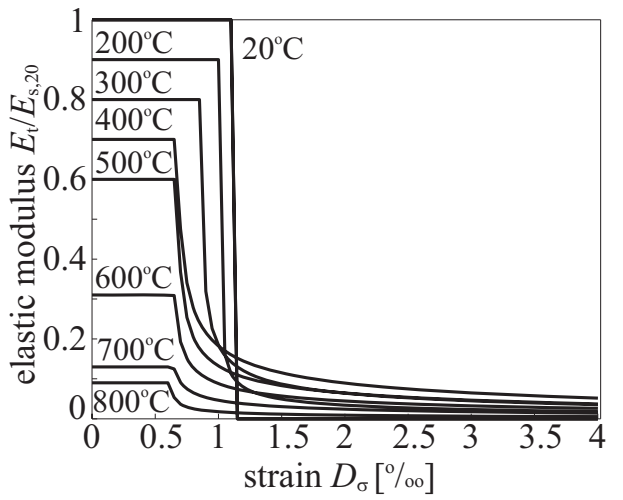

Fig. 4. (a) Stress-strain law of steel (in tension and in compression) (Eurocode 3, 2003). (b) Elastic modulus vs. strain.

in Table 6 for a column made of profile HEA 300 and being subjected to the ISO 834 fire. The figures in the table indicate, however, that the differences in $t_{\mathrm{cr}}$ are negligible, if $\Delta t$ is less than about 20 seconds. As expected, $T_{\mathrm{cr}}$ is insensitive indeed to the value of $\Delta t$.

Table 6. The effect of the time step, $\Delta t$, on the accuracy of $t_{\mathrm{cr}}$ and $T_{\mathrm{cr}}$ (HEA 300 , $\left.\lambda_{\mathrm{cr}}=40\right)$.

\begin{tabular}{cccccccc}
\hline$\Delta t[s]$ & 1 & 5 & 10 & 20 & 60 & 120 & 300 \\
\hline$t_{\mathrm{cr}}[\mathrm{min}]$ & 12.1779 & 12.1833 & 12.1906 & 12.2071 & 12.2887 & 12.4407 & 13.1105 \\
$T_{\mathrm{cr}}\left[{ }^{\circ} \mathrm{C}\right]$ & 471.2 & 471.2 & 471.2 & 471.2 & 471.2 & 471.2 & 471.2 \\
\hline
\end{tabular}

In what follows, we systematically analyse various effects on buckling of steel columns in fire.

\subsection{The effect of fire regime and material model}

Our first analysis is concerned with the effects of the fire regime and the material model on buckling of an axially unrestrained steel column (PPC, $\left.\mu_{H}=0\right)$. Two 
material models are employed: a perfectly elastic material and an elasto-plastic material (see Fig. 4a). The same dependence on temperature is assumed for elastic modulus $E_{\mathrm{s}, T}$ for both perfectly elastic and elasto-plastic material model, employing the expression $E_{\mathrm{s}, T}=k_{E, T} E_{\mathrm{s}, 20}$. In the analyses, the following data were used: section HEA 300, steel S 235 and load $F=F_{\text {cr }}=0.5 \mathcal{N}_{\text {ult,20. The related ultimate }}$ axial bearing capacity is $\mathcal{N}_{\text {ult } 20}=1327.75 \mathrm{kN}$. Fig. $5 \mathrm{a}$ shows the variation of the critical time, $t_{\mathrm{cr}}$, with the column slenderness, $\lambda=\lambda_{\mathrm{PPC}}=L \sqrt{A / J}$, for the ISO 834 and natural fires. The related variation of the critical temperature, $T_{\mathrm{cr}}$, is presented in Fig. 5b. If compared to the natural fire, the ISO 834 fire results in substantially smaller critical times for both material models and any column slenderness. In contrast, the critical temperature graphs coincide for the two fire regimes and are thus independent on how fire develops (Fig. 5b). As expected, buckling of very slender columns $(\lambda>115)$ still occurs in the elastic range of material; the material non-linearity is, however, essential for less slender columns. "Short" elastic columns with the slenderness less than about 75 experience neither buckling nor the fracture of material. Points $A^{*}$ and $A$ in Figs. 5a and 5b mark the exact positions needed to determine these particular slendernesses.

\subsection{The effect of boundary condition}

Fully analogous conclusions as stated above hold true for any Euler's column. This can be observed in Fig. $6 \mathrm{~b}$ where the graph of the critical temperature as a function of the column slenderness is depicted. Here, the column slenderness is defined as $\lambda=L_{\mathrm{u}} \sqrt{A / J}$, where $L_{\mathrm{u}}$ is the buckling length of the particular column under consideration. As already discussed, the buckling length remains constant during the temperature increase; thus, $L_{\mathrm{u}}=2$ for the FC column, and $L_{\mathrm{u}}=0.5$ for the FFC column (Table 3). If instead we employ the same slenderness for all columns, 
(a) $F_{\mathrm{cr}}=0.5 \mathcal{N}_{\text {ult }, 20}, \mu_{\mathrm{H}}=0$

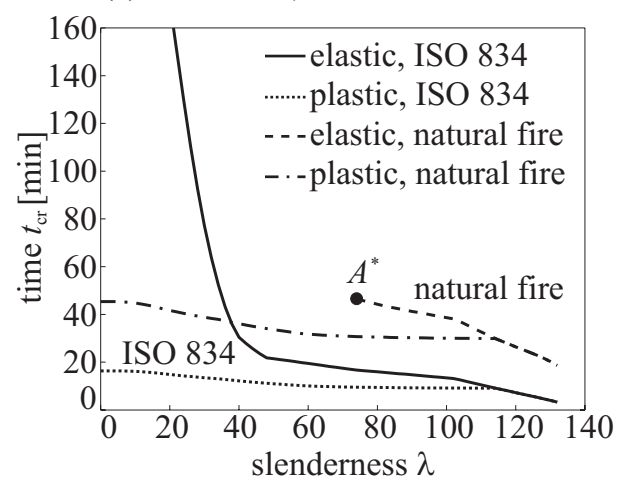

(b) $F_{\mathrm{cr}}=0.5 \mathcal{N}_{\text {ult } 20}, \mu_{\mathrm{H}}=0$

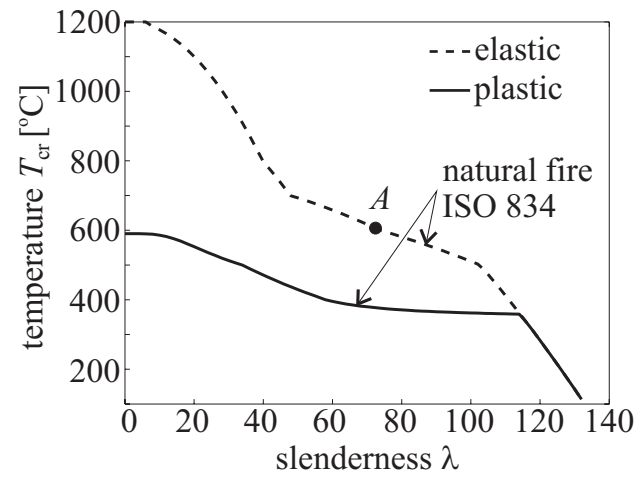

Fig. 5. Euler's columns. The effect of the fire regime and the material model on buckling of steel columns in fire. (a) Buckling time, $t_{\mathrm{cr}}$ (b) buckling temperature, $T_{\mathrm{cr}}$.

say $\lambda_{\mathrm{PPC}}$ as in Fig. 6a, the graphs do not coincide. As we see from this figure, the cantilever column is more prone to buckling compared to the fix-fix column.

(a) $F_{\text {cr }}=0.5 \mathcal{N}_{\text {ult, } 20}, \mu_{\mathrm{H}}=0$

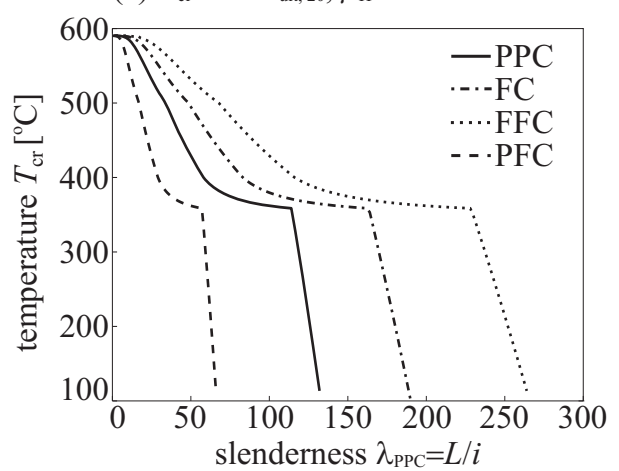

(b) $F_{\text {cr }}=0.5 \mathcal{N}_{\text {ult } 20}, \mu_{\mathrm{H}}=0$

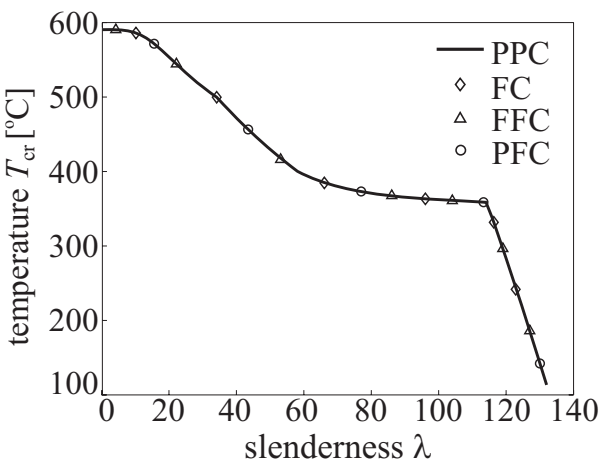

Fig. 6. Euler's columns. The effect of boundary conditions on buckling of steel columns in fire.

\subsection{The effect of the cross-section}

The effect of properties of the cross-section on buckling is very much within our expectations (Fig. 7). The effects were analysed for two fire regimes. We employed 
only steel S 235. The PPC column was subjected to $F_{\text {cr }}=0.5 \mathcal{N}_{\text {ult }, 20}=1327.75 \mathrm{kN}$. The column with section IPE 300, which has the smallest moment of inertia, buckled first. The column with section HEB 400 buckled the last despite the fact that it has not the largest moment of inertia. This is due to its small section factor. As indicated by Eq. (2.1), the transfer of temperature over the cross-section is proportional to the section factor. Consequently, smaller the factor, bigger is the delay of temperature. Hence buckling occurred much earlier in the columns having a large section factor. For a relatively short column, buckling may even not take place in natural fire, if the column is made from the HEA 500 or HEB 400 sections. This is indicated by points $A$ and $B$ in Fig. $7 \mathrm{~b}$.

(a) ISO $834, F_{\text {cr }}=0.5 \mathcal{N}_{\text {ult }, 20}, \mu_{\mathrm{H}}=0$

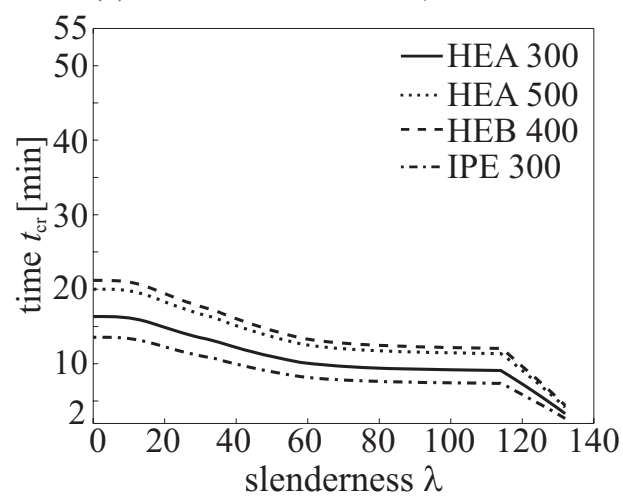

(b) natural fire, $F_{\mathrm{cr}}=0.5 \mathcal{N}_{\mathrm{ult}, 20}, \mu_{\mathrm{H}}=0$

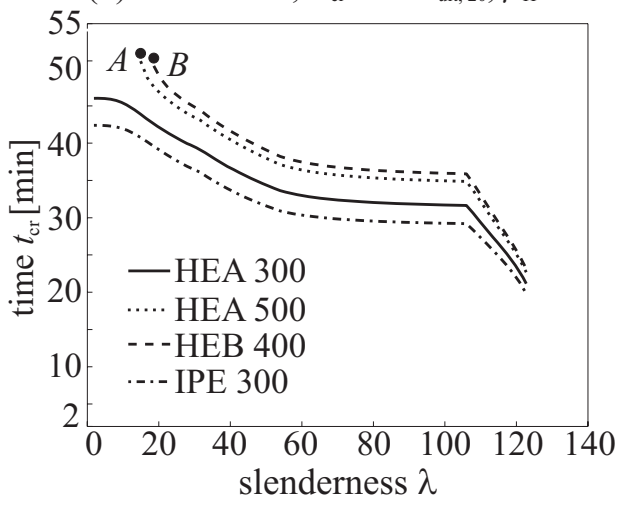

Fig. 7. Euler's columns. The effect of the cross-section on buckling of steel column in fire for two fire regimes. (a) ISO 834 (ISO 834, 1975), and (b) natural fire (Srpčič, 1991).

\subsection{The effect of yield strength and load ratio}

Next we analyze the effects of yield strength, $f_{\mathrm{y}, T}$, and load ratio on buckling of a steel column exposed to high temperatures (Fig. 8). The columns were assumed to be subjected to three different axial loads, i.e. $F_{\text {cr }}=0.3 F_{\text {ref }}, F_{\text {cr }}=0.5 F_{\text {ref }}$ 
and $F_{\text {cr }}=0.7 F_{\text {ref }}$, where the reference load, $F_{\text {ref }}$, was taken to be equal to the ultimate bearing capacity of the HEA 300 section made of steel S 235 at the room temperature $\left(F_{\text {ref }}=\mathcal{N}_{\text {ult,20 }}=2655.5 \mathrm{kN}\right)$. As expected, buckling occurs first for the columns with the lowest yield strength. Particularly in the range $\lambda>50$, the effect of yield strength on the buckling temperature is rather important. Its effect on the separation point between elastic and plastic buckling is also substantial, which is clearly observed in Fig. 8. This point occurs at $\lambda \cong 135$ for $F_{\text {cr }}=0.3 F_{\text {ref }}$, at $\lambda \cong 115$ for $F_{\text {cr }}=0.5 F_{\text {ref }}$ and at $\lambda \cong 100$ for $F_{\text {cr }}=0.7 F_{\text {ref }}$ (Fig. 8).

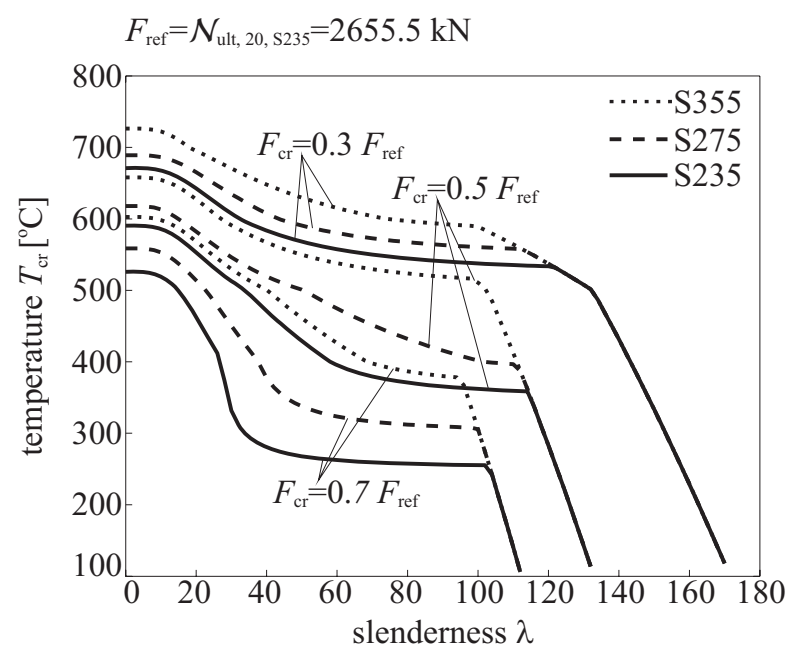

Fig. 8. Euler's columns. The effect of yield strength, $f_{\mathrm{y}, T}$, and the load ratio on buckling of steel columns in fire.

\subsection{The effect of material model}

The effect of the adopted material model on the buckling resistance is shown in Fig. 9, where the critical stress ratio, $\sigma_{\mathrm{cr}} / \sigma_{\mathrm{y}, 20}$, vs. the column slenderness is depicted for the range of temperatures from $20^{\circ} \mathrm{C}$ to $800^{\circ} \mathrm{C}$. The drop of the critical stress ratio with temperature is significant. For instance, the buckling resistance of 
a column with slenderness $\lambda=60$ at $T=500^{\circ} \mathrm{C}$ is about $41 \%$ and at $T=800^{\circ} \mathrm{C}$ only about $5 \%$ of the related resistance at the room temperature. The point, separating elastic and plastic buckling regimes, also notably varies with the slenderness. A somewhat unexpected is found the position of the point separating the loss of stability by buckling and the material failure of the column. At the room temperature, the slenderness as high as 93 triggers buckling, while at temperatures higher than $200^{\circ} \mathrm{C}$, the slenderness of about 2 is already sufficient for buckling. Hence, in practice buckling will appear to be the only mode of fracture of columns due to fire.

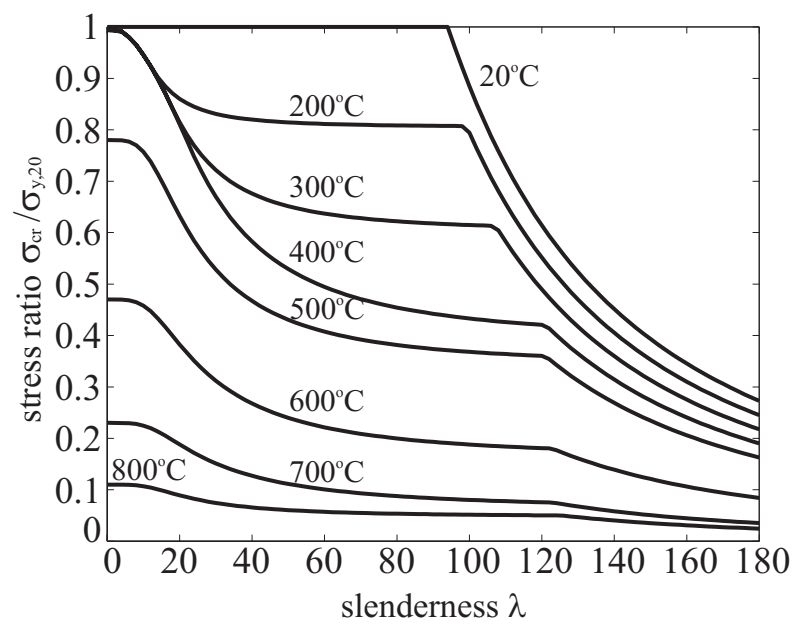

Fig. 9. Euler's columns. Relationship between the critical stress ratio, $\sigma_{\mathrm{cr}} / \sigma_{\mathrm{y}, 20}$, and the slenderness, $\lambda$, at different temperatures.

\subsection{The effect of axial restraints}

Our final discussion directs into the effect of the stiffness of axial restraints. The

HEA 300 section, made of steel S 235, is employed. Two load ratios were analysed: $F_{\text {cr }}=0.3 \mathcal{N}_{\text {ult }, 20}$ and $0.5 \mathcal{N}_{\text {ult }, 20}$, where $\mathcal{N}_{\text {ult }, 20}=2655.5 \mathrm{kN}$. For convenience, the 
stiffness of the axial restraint, $\mu_{H}$, is normalized, and the normalized quantity denoted by $\beta_{H}=L \mu_{H} / E_{\mathrm{s}, 20} A$. Here $L=5 \mathrm{~m}, E_{\mathrm{s}, 20}=21000 \mathrm{kN} / \mathrm{cm}^{2}$ and $A=$ $159 \mathrm{~cm}^{2}$. The analysis was preformed for $\beta_{H}=0,0.01,0.05,0.1,1$ and 5 . Fig. 10 depicts the variation of the critical temperature with the slenderness of the column. As we see from the figure, the stiffness of the axial restraint can either improve or reduce the buckling resistance of the column. That is, the buckling resistance is dramatically reduced for sufficiently slender columns, $\lambda>16$, while it can be much improved for the columns having $\lambda<16$. Such a controversial behaviour can be explained with the help of Fig. 11, where we show the variation of the normalized axial force, $\|\mathcal{N}\|=|\mathcal{N}| /\left(0.3 \mathcal{N}_{\text {ult,20 }}\right)$, and the normalized tangent bending stiffness of the cross-section, $\left\|C_{22}\right\|=E_{\mathrm{t}} J / E_{\mathrm{s}, 20} J$, with temperature. The variations for two column slendernesses $(\lambda=10$ and 60$)$ and for two axial restraints $\left(\beta_{H}=0.01\right.$ and 1) are shown. When temperature increases in the less slender column $(\lambda=10)$, the bending stiffness of the cross-section suddenly drops down, causing the instability of the column. For the slender column, $\lambda=60$, the bending stiffness decreases much more slowly; hence, the size of axial force $\mathcal{N}$, and not the bending stiffness becomes critical for buckling. A very different graphs of the axial force are observed for columns with $\lambda=10$ and different $\beta_{H}$ 's (Fig. 11a). There, buckling for $\beta_{H}=0.01$ takes place at a totally different relationship between the axial force and the bending stiffness of the cross-section compared to $\beta_{H}=1$.

A very similar behaviour of columns is observed, if the restraint is rigid $\left(\mu_{H}=\right.$ $\infty)$ and the column is pin-like supported at both ends. Some further results for the critical temperature, the related normalized axial force and the normalized bending stiffness of the cross-section are given in Table 7. 
(a) $F_{\text {cr }}=0.3 \mathcal{N}_{\text {ult, } 20}$

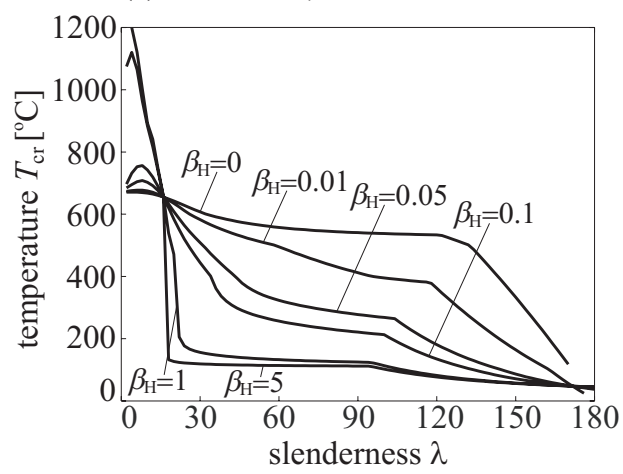

(b) $F_{\text {cr }}=0.5 \mathcal{N}_{\text {ult, } 20}$

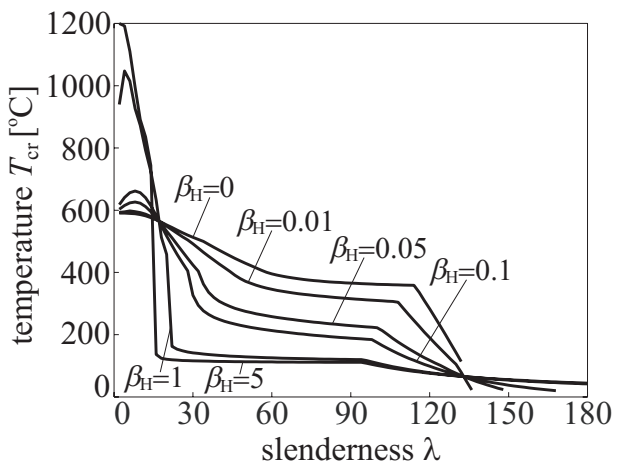

Fig. 10. Euler's columns. The effects of the stiffnes of the axial restraint on the critical temperature $T_{\text {cr. }}$. (a) $F_{\text {cr }}=0.3 \mathcal{N}_{\text {ult }, 20}$; (b) $F_{\text {cr }}=0.5 \mathcal{N}_{\text {ult }, 20}$.

(a) $\lambda=10$

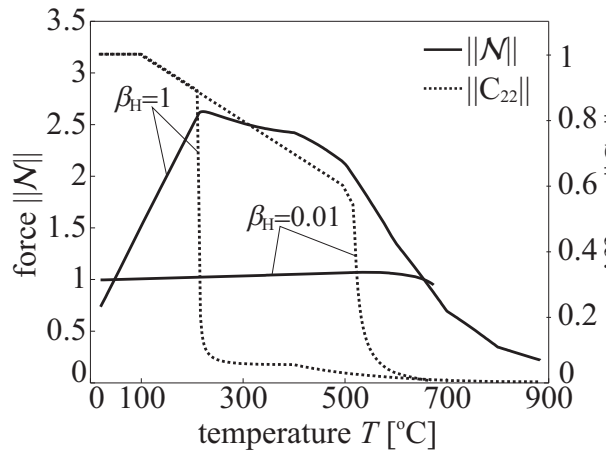

(b) $\lambda=60$

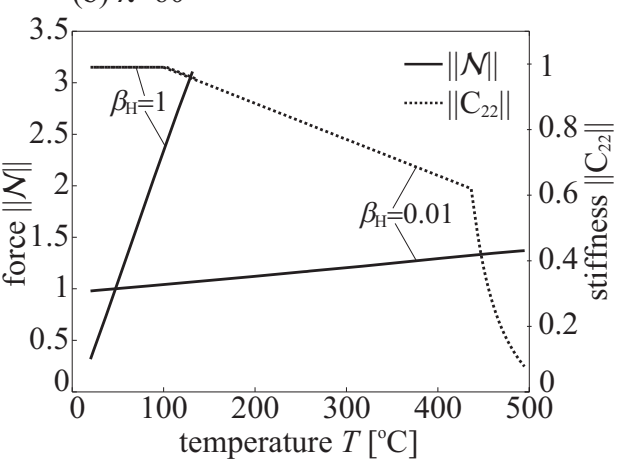

Fig. 11. Euler's columns. The variation of the normalized axial force, $\|\mathcal{N}\|=|\mathcal{N}| /\left(0.3 \mathcal{N}_{\text {ult,20 }}\right)$, and the normalized bending stiffness, $\left\|C_{22}\right\|=E_{\mathrm{t}} / E_{\mathrm{s}, 20}$, with temperature $T$. (a) $\lambda=10$; (b) $\lambda=60$.

\section{Conclusions}

We presented an analytical procedure for the determination of the critical temperature of an axially loaded, axially restrained, geometrically perfect steel column, if exposed to a temperature increase, which is characteristic for the standard or natural fire. Within the assumption that steel at high temperature behaves in accordance with the material model proposed by European standard Eurocode $3,{ }^{1}$ the critical 
Table 7. The effect of $\beta_{H}$ and $\lambda$ on the critical temperature, axial force and cross-sectional bending stiffness of axially restrained steel columns, $F=0 \mathrm{kN}$.

\begin{tabular}{ccccccccc}
\hline$\lambda$ & & 8 & 12 & 13 & 21 & 94 & 120 & 180 \\
\hline \multirow{2}{*}{$T_{\text {cr }}\left[{ }^{\circ} C\right]$} & $\beta_{H}=\infty$ & 1014 & 847 & 113 & 109 & 109 & 76 & 45 \\
& $\beta_{H}=5$ & 1014 & 848 & 794 & 133 & 114 & 78 & 46 \\
& $\beta_{H}=0.05$ & 1094 & 904 & 887 & 735 & 344 & 273 & 118 \\
& $\beta_{H}=0.01$ & 1161 & 1071 & 1046 & 885 & 582 & 552 & 319 \\
\hline & $\beta_{H}=\infty$ & 0.037 & 0.082 & 0.977 & 0.983 & 0.983 & 0.614 & 0.273 \\
& $\beta_{H}=5$ & 0.036 & 0.081 & 0.109 & 0.941 & 0.974 & 0.614 & 0.273 \\
$\|\mathcal{N}\|$ & $\beta_{H}=1$ & 0.035 & 0.078 & 0.103 & 0.677 & 0.940 & 0.614 & 0.273 \\
& $\beta_{H}=0.05$ & 0.021 & 0.055 & 0.061 & 0.150 & 0.535 & 0.506 & 0.268 \\
& $\beta_{H}=0.01$ & 0.008 & 0.024 & 0.028 & 0.054 & 0.222 & 0.266 & 0.212 \\
\hline & $\beta_{H}=\infty$ & 0.0003 & 0.0013 & 0.0187 & 0.0491 & 0.0493 & 1 & 1 \\
& $\beta_{H}=5$ & 0.0003 & 0.0013 & 0.0021 & 0.0470 & 0.1083 & 1 & 1 \\
$\left\|C_{22}\right\|$ & $\beta_{H}=1$ & 0.0003 & 0.0013 & 0.0020 & 0.0338 & 0.9405 & 1 & 1 \\
& $\beta_{H}=0.05$ & 0.0002 & 0.0009 & 0.0012 & 0.0075 & 0.5373 & 0.8274 & 0.9816 \\
& $\beta_{H}=0.01$ & 0.0001 & 0.0004 & 0.0005 & 0.0027 & 0.2239 & 0.4367 & 0.7809 \\
\hline
\end{tabular}

temperature is determined exactly. As a result of extensive parametric analyses, the following findings can be stated:

- The dependence of material parameters on temperature, the slenderness of the column and the shape of the cross-section, all have a significant effect on the critical temperature.

- Buckling lengths of Euler's columns are not subject to change during fire.

- The critical temperature is found to be a unique function of the slenderness of a steel column for a given cross-section, the loading level, and for any of Euler's columns.

- For the axially restrained columns, the buckling resistance decreases with an increase of the stiffness of the axial restraint for columns with slenderness 
$\lambda>16$, and increases for columns with $\lambda<16$.

Of a particular interest for a structural engineer are the findings that the critical temperature is a unique function of the slenderness for all Euler's columns and that buckling rather than the over-strengthening of the cross-section is the mode of collapse of the steel column subjected to a fire-like increase of temperature.

\section{Acknowledgement}

The work of T. Hozjan was financially supported by the Ministry of Education, Science and Sport and by the Ministry of the Economy of the Republic of Slovenia under contract 3311-04-831816. The support is gratefully acknowledged.

\section{References}

1. Eurocode 3, Design of Steel Structures, Part 1.2: Structural fire design (final draft), European Committee for Standardization, 2003.

2. BS5950-8, Structural Use of Steelwork in Building - Part 8: Code of Practice for Fire Resistant Design, London: British Standard Institution, 2003.

3. ISO 834, Fire resistance tests - elements of building constructions, International Standard, 1975.

4. I.W. Burgess, A.O. Olawale, and R.J. Plank, "Failure of steel columns in fire," Fire Safety J. 18, pp. 183-201, 1992.

5. J.M. Franssen and J.C. Dotreppe, "Fire resistance of columns in steel frames," Fire Safety J. 19, pp. 159-175, 1992.

6. J.M. Franssen, D. Talamona, J. Kruppa and L.G. Cajot, "Stability of steel columns in case of fire: Numerical modeling," J. Struct. Eng. ASCE 123(6), pp. 713-720, 1998.

7. Z.F. Huang, I.W. Burgess and R.J. Plank, "Non-linear structural modeling of a fire test subject to high restraint," Fire Safety J. 36, pp. 795-814, 2001.

8. Z.F. Huang and K.H. Tan, "Effects of external bending moments and heating schemes on the responses of thermally restrained steel columns," Eng. Struct. 26(6), pp. 769$780,2004$.

9. Z.F. Huang, K.H. Tan and S.K. Ting, "Heating rate and boundary restraint effects on fire resistance of steel columns with creep," Eng. Struct. 28, pp. 805-817, 2006.

10. I.C. Neves, "The critical temperature of steel columns with restrained thermal elongation," J. Construct. Steel Res. 24, pp. 211-227, 1995.

11. I.C. Neves, J.C. Valente and J.P.C. Rodrigues, "Thermal restraint and fire resistance of columns," Fire Safety J. 37, pp. 753-771, 2002.

12. H. Oda and T. Usami, "Stability design of steel plane frames by second-order elastic analysis," Eng. Struct. 19, pp. 617-627, 1997. 
13. S. Srpčič, Numerical analysis of fire effects on steel frames, $\mathrm{PhD}$ Thesis, University of Ljubljana, Faculty of Civil and Geodetic Engineering, Slovenia (in Slovenian), 1991.

14. K.H. Tan, S.K. Ting and Z.F. Huang, "Visco-elasto-plastic analysis of steel frames in fire," J. Struct. Eng. ASCE 128(1), pp. 105-114, 2002.

15. Vila Real, P.M.M., Hopes, N., da Silva, S., Piloto, P. and Franssen, J.M., "Numerical modelling of steel beam-columns in case of fire-comparison with Eurocode 3". Fire Safety J., 39, 23-39, 2004.

16. Y.C. Wang and D.B. Moore, "Steel frames in fire: analysis," Eng. Struct. 17(6), pp. 462-472, 1995.

17. Y.C. Wang, "The effects of frame continuity on the behaviour of steel columns under fire conditions and fire resistant design proposals," J. Const. Steel Res. 41, pp. 93-111, 1997.

18. Q. Wang and J.G. CHASE, "Buckling analysis of cracked column structures and piezoelectric-based repair and enhancement of axial load capacity," Int. J. Struct. Stab. Dyn. 3(1), pp. 17-33, 2003.

19. Z.F. Huang and K.H. Tan, "Analytical fire resistance of axially restrained steel columns," J. Struct. Eng. ASCE 129(11), pp. 1531-1537, 2003.

20. N. Krauberger, M. Saje, I. Planinc and S. Bratina, "Exact buckling load of a restrained RC column," Struct. Eng. Mech. 27(3), pp. 293-310, 2007.

21. G.M. Newman, J.T. Robinson and C.G. Bailey, Fire safe design: A new approach to multi-storey steel-framed buildings, Berkshire, SCI, 2001.

22. F. Ali and D. O'Connor, "Structural performance of rotationally restrained steel columns in fire," Fire Safety J. 36, pp. 679-691, 2001.

23. W. Skowronski, "Buckling fire endurance of steel columns in fire," J. Struct. Eng. ASCE 119(6), pp. 1712-1732, 1993.

24. W.S. Toh, K.H. Tan and T.C. Fung, "Compressive resistance of steel columns in fire," J. Struct. Eng. ASCE 126(3), pp. 398-405, 2000.

25. C.Y Tang, K.H. Tan and S.K. Ting, "Basis and application of a simple interaction formula for steel columns under fire conditions," J. Struct. Eng. ASCE 127(10), pp. 1206-1213, 2001.

26. M. Eisenberger and H. Ambarsumian, "Buckling of columns with internal slide release," Int. J. Struct. Stab. Dyn. 2(4), pp. 593-598, 2002.

27. B. Yang and D.H. Park, "Exact buckling analysis of constrained steeped columns," Int. J. Struct. Stab. Dyn. 3(2), pp. 143-167, 2003.

28. E. Reissner, "On one-dimensional finite-strain beam theory: The plane problem," $J$. Appl. Math. Phys. (ZAMP) 23(5), pp.795-804, 1972.

29. C. M. Wang, C.Y. Reddy and J.N. Reddy, Exact solutions for buckling structural members, CRC Press LLC, New York, 2005.

30. J.P.C. Rodrigues, I.C. Neves and J.C. Valente, "Experimental research on the critical temperature of compressed steel elements with restrained thermal elongation," Fire Safety J. 35, pp. 77-98, 2000.

31. Eurocode 1, Actions on structures, Part 1.2: General actions - Actions on structures exposed to fire, European Committee for Standardization, 2002.

32. Z.C. Ma and P. Mäkeläinen, "Parametric temperature-time curves of medium compartment fires for structural design," Fire Safety J. 34, pp. 361-375, 2000.

33. S.E. Magnusson and S. Thelandersson, "Temperature-time curves of complete process of fire development," Acta Polytecnica Scandinavica, Civil Engineering and Building Construction Series, No. 65, Stockholm, 1970.

34. E.R.G Eckert and R.M. Drake, Analysis of heat and mass transfer, McGraw-Hill Book Co., New York, 1972. 
June 29, $2009 \quad 19: 43$

Buckling of an axially restrained steel column under fire loading 33

35. J.A. Purkiss, "Developments in the fire safety design of structural steelwork," $J$. Const. Steel Res. 11, pp. 149-173, 1988.

36. H.B. Keller, "Nonlinear bifurcation," J. Diff. Eq. 7(3) , pp. 417-434, 1970. 